\title{
Public Health Laboratory Service enzyme linked immunosorbent assay for detecting Toxoplasma specific IgM antibody
}

\author{
R A PAYNE,* D H M JOYNSON, ${ }^{*}$ A H BALFOUR, $\dagger$ J P HARFORD, $\dagger$ D G FLECK, \\ M MYTHEN, $\ddagger$ R J SAUNDERS $\dagger$ \\ From the *Swansea Public Health Laboratory, Wales; the †Leeds Public Health Laboratory; and the $\ddagger$ Tooting \\ Public Health Laboratory, London
}

SUMMARY An enzyme linked immunosorbent assay (ELISA) based on the antibody class capture method for the detection of specific IgM against Toxoplasma gondii, using the microtitre plate format, was developed. Antigen binding was detected using a monoclonal antibody, CIE3, conjugated to horseradish peroxidase. Prior mixing of the conjugate and antigen improved the stability of these reagents as well as removing an incubation stage from the assay. The incubation time of less than four hours permits a rapid throughput of specimens.

Using the assay, a total of 163 sera were examined in a three centre study and good agreement was found. Results were expressed as arbitrary enzyme immunoassay units (EIUs) against a freeze dried standard. Throughout the study the standard serum showed a coefficient of variation less than $10 \%$ across the microtitre plate. By measuring IgM titres in patients having toxoplasmic lymphadenopathy with a known date of onset, IgM class antibodies were shown to peak at two months, persisting for about six months. In addition, a case of laboratory acquired toxoplasmosis was monitored. Sera shown to contain rheumatoid factor and antinuclear factor did not give false positive results.

This rapid, robust, and simplified assay is used by the Public Health Laboratory Service Toxoplasma Reference Units and will provide a standard with which other assays can be compared.

The value of enzyme immunosorbent assays for the detection of specific IgM class antibodies in both acute and congenital toxoplasmosis is now well established. ${ }^{1}$ These assays have been shown to be more sensitive and specific than the indirect immunofluorescence test, ${ }^{2}$ particularly when the antibody class capture system is used. ${ }^{3}$ The use of antibody class capture system at the Swansea Public Health Laboratory Service (PHLS) Toxoplasmosis Reference Unit was described in an article published in $1982,{ }^{2}$ while both the Leeds and Tooting Units also have several years experience with modifications of the assay.

Further modifications, including the use of microtitre plates and the monoclonal antibody (CIE3), have led to the development of a rapid, simplified,

Accepted for publication 24 September 1986 and relatively robust assay.

This study was performed to establish uniformity of testing and reporting between the three PHLS Toxoplasma Reference Units in England and Wales and to establish a standard assay with which other assays for the detection of toxoplasma specific IgM class antibodies could be compared.

\section{Material and methods}

PRODUCTION OF MONOCLONAL ANTIBODY CIE3 This work was carried out at the Leeds PHL (unpublished data). Balb/c mice were each infected intraperitoneally with 10 cysts of the Gleadle strain of Toxoplasma gondii on days 1 and 28, followed by 100 trophozoites of the RH strain intravenously three days before fusion. Fusion was carried out with myeloma cells of the non-immunoglobulin secretory line designated P3-X63-Ag8.653 that were resistant to 
8-azaguanine. Antibody production after fusion was monitored from day 10 by the Toxoplasma dye test. ${ }^{4}$

One hybridoma was found to produce an antibody (CIE3) with high specific activity against a $35 \mathrm{Kd}$ surface membrane antigen of the organism. After cloning $10^{6}$ cells were injected intraperitoneally into Balb/c mice previously primed with Pristane (Sigma Ltd). When ascites was evident, it was tapped using a 14 gauge needle. The fluid was pooled, clarified by centrifugation, and stored at $-20^{\circ} \mathrm{C}$. When compared with the World Health Organisation AntiToxoplasma Standard Reference Serum (WHO, International Laboratory for Biological Standards, Statens Seruminstitut, DK 2300, Copenhagen, Denmark), dye test titres equivalent to $32000 \mathrm{IU} / \mathrm{ml}$ were obtained with this fluid.

\section{CONJUGATION PROCEDURE}

CIE3, an antibody of the $\mathrm{IgG}_{3}$ isotype, was separated from the mouse ascitic fluid by affinity chromatography. A column measuring $10 \times 1 \mathrm{~cm}$ containing Sepharose protein A CL-4B (Pharmacia) was set up and equilibriated with $25 \mathrm{ml}$ of $10 \mathrm{mM}$ phosphate buffered saline (PBS) $\mathrm{pH} \mathrm{7.3}$. Five $\mathrm{ml}$ of the CIE3 mouse ascites was passed through and the column washed with PBS until the absorbance at $280 \mathrm{~nm}$ was zero. The captured antibody was eluted with a $50 \mathrm{mM}$ sodium acetate solution at $\mathrm{pH} 4.3$ and dialysed overnight against $10 \mathrm{mM} \mathrm{Na} \mathrm{CO}_{3}$ solution. It was then conjugated to horseradish peroxidase by the method of Wilson and Nakane ${ }^{5}$ and stored as small aliquots under liquid nitrogen.

\section{TOXOPLASMA ANTIGEN}

The antigen used throughout this study was produced from membranes of hen eggs infected with Toxoplasma. ${ }^{6}$ The chorioallantoic membranes of 13 day old chick embryos were infected with a suspension of the RH strain of $T$ gondii. The trophozoites of the RH strain were obtained from the peritoneal cavities of mice infected three days previously. After seven days' incubation the membranes were removed, suspended in PBS, and macerated. The suspension was then frozen at $-70^{\circ} \mathrm{C}$ and thawed at $37^{\circ} \mathrm{C}$ on three occasions before being centrifuged at $2500 \mathrm{~g}$ for 10 minutes. The supernatant constituted the antigen and was stored at $-20^{\circ} \mathrm{C}$.

\section{ANTIGEN AND CONJUGATE REAGENT}

The approximate titre of both the antigen and the conjugate was determined by chessboard titration. The combined reagent was prepared by adding $100 \mu \mathrm{l}$ of the conjugate to $100 \mathrm{ml}$ of the antigen, mixing thoroughly, and incubating for 24 hours at $37^{\circ} \mathrm{C}$. It was then divided into $5 \mathrm{ml}$ volumes and stored at $4^{\circ} \mathrm{C}$. Several batches prepared over six months had work- ing titres varying between $1 / 20$ and $1 / 60$ when titrated against standard sera. The antigen and conjugate used at the three laboratories was prepared and distributed by the Swansea PHL. All other reagents were obtained and prepared locally.

\section{CAPTURE ANTIBODY}

The optimum dilution of a rabbit antihuman IgM (Dako, Copenhagen) was determined by chessboard titration and found to be $1 / 1000$ when used in the test conditions described. The $50 \mathrm{mM}$ carbonate and bicarbonate coating buffer ( $\mathrm{pH} \mathrm{9.6)} \mathrm{for} \mathrm{the} \mathrm{antihuman}$ IgM was prepared by dissolving $1.56 \mathrm{~g}$ of $\mathrm{Na}_{2} \mathrm{CO}_{3}$ and $2.5 \mathrm{~g}$ of $\mathrm{NaHCO}_{3}$ in 1 litre of water. This could be used for up to two weeks if stored at $4^{\circ} \mathrm{C}$.

\section{SUBSTRATE}

The chromogenic substrate used was $3,3^{\prime}, 5,5^{\prime}$, tetramethylbenzidene (TMB) (Miles Scientific, Naperville, USA). The stock solution was prepared by dissolving $100 \mathrm{mg}$ TMB in $10 \mathrm{ml}$ of dimethylsulphoxide. This was stored at room temperature in a dark bottle. Citric acid and sodium acetate buffer $(100 \mathrm{mM})(\mathrm{pH} \mathrm{6.0})$ was prepared by dissolving $16.4 \mathrm{~g}$ of sodium acetate in 2 litres of water and $2.1 \mathrm{~g}$ of citric acid in $100 \mathrm{ml}$ of water. The citric acid solution was added to the sodium acetate solution to bring the $\mathrm{pH}$ to $6 \cdot 0$. This was then distributed in $100 \mathrm{ml}$ volumes, autoclaved at 10 psi/10 minutes, and stored at room temperature. Just before use $250 \mu$ l of TMB solution was pipetted into a clean universal container and $25 \mathrm{ml}$ of the $\mathrm{pH} 6.0$ buffer added rapidly, with thorough mixing, followed by $25 \mu 1$ of $6 \%$ (20 volumes) $\mathrm{H}_{2} \mathrm{O}_{2}$.

\section{WASH SOLUTION AND DILUENT}

The wash solution consisted of PBS with $0.05 \%(\mathrm{v} / \mathrm{v})$ Tween 20 (PBST) added. The diluent for both the serum specimens and antigen and conjugate reagent was PBST with the addition of $1 \%(w / v)$ bovine serum albumin (PBST-BSA).

\section{EQUIPMENT}

All the wash procedures at Swansea were carried out with a Titertek Microplate Washer 120 and absorbance readings were made with a Titertek Multiskan MCC (Flow Laboratories, Rickmansworth, Herts, England), while in Tooting a Dynatech automatic plate washer (Dynatech Laboratories, Billinghurst, Sussex) and a Titertek Multiskan 10 were used. At Leeds the wash procedure was carried out by hand, immersing the plate in wash solution, emptying, and tapping on to blotting paper. This was repeated six times. The absorbance readings were made with an Artek Automatic Plate Reader (New Brunswick Scientific Ltd, Watford). 
SER UM SA M PLES

From sera received at the Swansea PHL for Toxoplasma antibody tests, 89 were selected according to the stated date of onset of lymphadenopathy and dye test titre. These included single specimens from 75 patients and sequential specimens from four patients. Except for the later specimens from these four patients, all sera had dye test titres equivalent to 500 $\mathrm{IU} / \mathrm{ml}$ or more. A further $\mathbf{4 0}$ sera were from patients whose clinical details were not available but who had Toxoplasma antibody titres varying from 2 to 2000 $\mathrm{IU} / \mathrm{ml}$, a group of 20 sera shown to contain rheumatoid factor but no Toxoplasma antibody, and five containing antinuclear factor were also included. In addition, sequential serum samples from a case of laboratory acquired toxoplasmosis were examined. Aliquots from the above serum samples were sent to the Leeds and Tooting laboratories where they were stored at $-20^{\circ} \mathrm{C}$ until tested.

\section{UNIFOR MITY OF REPORTING}

This was achieved by expressing the results as enzyme immunoassay units (EIU), ${ }^{7}$ which are calculated from the following formula:

EIU $=\frac{\text { Test absorbance }- \text { Negative absorbance }}{\text { Reference absorbance }- \text { Negative absorbance }} \times 100$

CONTROLS

Two standard sera were used, one without Toxoplasma specific IgM for use as the negative control, and one containing Toxoplasma specific IgM for use as the reference control. The negative control selected was that used in the dye test as accessory factor and shown not to contain antibodies to $T$ gondii. The pos-

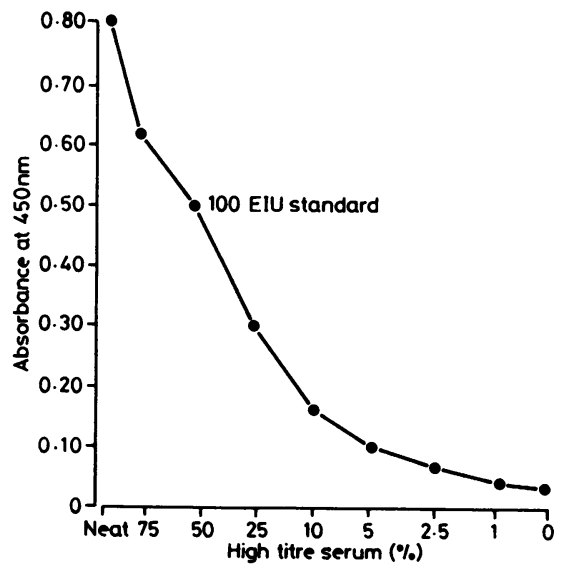

Fig 1 Standard regression curve for Toxoplasma IgM antibody ELISA: High titre serum was diluted in serum containing no antibodies against $T$ gondii. itive control was prepared from a pool of sera with high titres of Toxoplasma specific IgM antibody.

When dilutions of a serum containing high titres of Toxoplasma IgM are made in PBST-BSA and those dilutions measured by the antibody class capture assay, the resulting absorbance values vary little from each other, even at dilutions of $1 / 1000$. If, however, the dilutions are made in the negative control serum, the absorbance values are related to the amount of specific IgM present, due to competition for the available sites reducing the proportion of specific IgM able to bind to the solid phase. A standard regression curve was constructed from a range of such dilutions, each dilution being tested in the normal way at $1 / 1000$ in diluent (fig 1). The approximate mid point of the slope occurred with the high titre serum diluted in an equal volume of negative serum. This was given an arbitrary value of 100 EIU and used for the calculation of the test results. A unit value of $<25$ was considered to be negative, 26-40 as doubtful, 41-100 as positive, and $>100$ as strongly positive. A similar method of calibrating a standard serum for use in a rubella specific IgM capture method has been described by Tedder. ${ }^{8}$

An additional low level control in the range 20-30 EIU was included with each run to monitor the sensitivity of the assay in distinguishing negative and weakly reactive sera, as well as providing a visual check on the course of the reaction.

The control sera are kept in $200 \mu$ l volumes at the Swansea PHL in freeze-dried phials. Aliquots were diluted $1 / 1000$ in sterile diluent containing sodium azide $(0.08 \% \mathrm{w} / \mathrm{v})$ and issued to the other laboratories in this prediluted state. Experience has shown that the sera retain their titre for at least six months when diluted as described and stored at $4^{\circ} \mathrm{C}$. The control sera were included on every microtitre plate used in this study. They were loaded in sequence into wells near the top and the bottom of the plate so that the percentage coefficient of variation across the plate could be calculated. The controls consistently gave a percentage coefficient of variation of $<10 \%$.

\section{ELISA METHOD}

All tests were set up in flat bottomed Falcon Microtest polyvinyl chloride flexible assay plates (Becton Dickenson, California, USA). To $12 \mathrm{ml}$ of coating buffer, $12 \mu \mathrm{l}$ of antihuman IgM was added, mixed, and distributed in $100 \mu \mathrm{l}$ volumes to all wells of a microtitre plate. The plate was covered with a suitable lid and incubated for one hour at $37^{\circ} \mathrm{C}$. After incubation the microtitre plate was washed 10 times by machine (six times by hand at Leeds), the plate being reversed after five washes when a plate washer was used. After removing any remaining wash solution by tapping the plate on to blotting paper, $1 / 1000$ dilu- 
Table 1 Comparative classifications of IgM titres in 163 sera reported (No and classification of results not agreeing are shown in parentheses)

\begin{tabular}{llll}
\hline & Swansea & Leeds & Tooting \\
++ & 33 & 33 & $32(1+)$ \\
+ & 33 & $29(4++)$ & $29(4++)$ \\
$+/-$ & 14 & $13(1+)$ & $8(6+)$ \\
Negative & 83 & $82(1+/-)$ & $82(1+/-)$ \\
& & & \\
+ & Leeds & Swansea & Tooting \\
++ & 37 & $33(4+)$ & $35(2+)$ \\
+ & 30 & $29(1+/-)$ & $29(1++)$ \\
$+/-$ & 14 & $13(1$ negative) & $9(5+)$ \\
Negative & 82 & 82 & 82 \\
& & & Leeds \\
++ & 36 & $32(4+)$ & $35(1+)$ \\
+ & 36 & $29(1++, 6+/-)$ & $29(2++, 5+/-)$ \\
$+/-$ & 9 & $8(1$ negative $)$ & 9 \\
Negative & 82 & 82 & 82 \\
\hline
\end{tabular}

++ , strongly positive; + , positive; $+/-$, doubtful.

tions of test and control sera were added in $100 \mu \mathrm{l}$ volumes. After a further one hour of incubation at $37^{\circ} \mathrm{C}$ the plate was washed as previously described, $100 \mu$ l volumes of the antigen and conjugate reagent (diluted to titre) added to each well, and the plate incubated for one hour at $37^{\circ} \mathrm{C}$. The plate was washed and $100 \mu \mathrm{l}$ of freshly prepared substrate added to each well. After incubation for 30 minutes at room temperature the reaction was stopped by adding $25 \mu \mathrm{l}$ of $2 \mathrm{M} \mathrm{H}_{2} \mathrm{SO}_{4}$ (Aristar) to each well and mixing gently but thoroughly, this changed the colour of the positive reactions from blue to yellow. The absorbances were read at $450 \mathrm{~nm}$, recorded, and the EIU's determined.

\section{Results}

Of a total of 163 sera, Toxoplasma specific antibody was detected by all three centres in 80 sera and not detected in 82 sera. One result was recorded as negative at one centre and doubtful at the other two. The EIU values for this serum, however, were recorded as 23,26 , and 28 , respectively, all very close to the cut off point of 25 used for classification. Of the 82 sera found negative by the three laboratories, 20 had been shown to contain rheumatoid factor and five antinuclear factor. The results obtained at each laboratory were compared with those from the other two laboratories (table 1). While most of the sera were given the same classification by each centre, some differences were found, but there were no cases in which the differences exceeded one class.

The IgM response to Toxoplasma infection may vary considerably between patients (table 2). Case 3 showed a relatively weak response; specific IgM was just detectable at four months and negative at seven months. In contrast, in case 2 the response was stronger and persisted for 11 months.

Table 2 Results obtained with sequential sera from four patients with toxoplasmic lymphadenopathy

\begin{tabular}{|c|c|c|c|c|c|c|}
\hline \multirow{2}{*}{\multicolumn{2}{|c|}{ Case No }} & \multirow{2}{*}{$\begin{array}{l}\text { Months after onset of } \\
\text { lymphadenopathy }\end{array}$} & \multirow{2}{*}{$\begin{array}{l}\text { Swansea } \\
\text { dye test } \\
\text { result }(I U / \mathrm{ml})\end{array}$} & \multicolumn{3}{|c|}{ ELISA results } \\
\hline & & & & Swansea & Leeds & Tooting \\
\hline \multirow[t]{4}{*}{ Case 1: } & 1 & 1 & 4000 & + & ++ & ++ \\
\hline & 2 & 3 & 1000 & + & + & + \\
\hline & 3 & 7 & 500 & + & + & + \\
\hline & & 10 & 500 & + & + & + \\
\hline \multirow[t]{4}{*}{ Case 2: } & 1 & 2 & 2000 & ++ & ++ & ++ \\
\hline & 2 & 5 & 1000 & + & + & + \\
\hline & 3 & 7 & 250 & + & + & + \\
\hline & & 11 & 125 & $+1-$ & $+1-$ & $+1-$ \\
\hline \multirow[t]{3}{*}{ Case 3: } & 1 & 4 & 2000 & $+1-$ & $+1-$ & $+1-$ \\
\hline & 2 & 7 & 2000 & - & - & - \\
\hline & 3 & 9 & 500 & - & - & - \\
\hline \multirow[t]{3}{*}{ Case 4: } & 1 & 6 & 1000 & + & ++ & ++ \\
\hline & 2 & 11 & 1000 & - & - & - \\
\hline & 3 & 15 & 250 & - & - & - \\
\hline
\end{tabular}

++ , strongly positive; + , positive; $+/-$, doubtful; - , negative. 
280

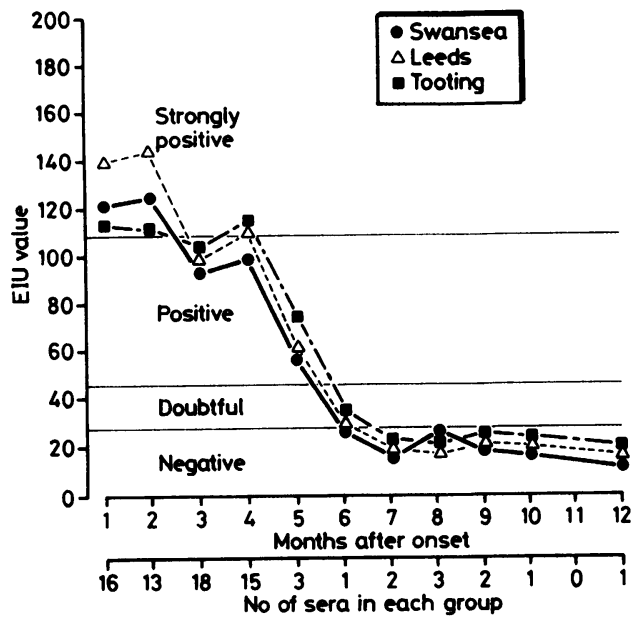

Fig 2 Persistence of $\operatorname{IgM}$ in 75 cases of toxoplasmic lymphadenopathy with known date of onset: geometric mean titres obtained for each group of sera at each centre are shown.

The mean EIU of each group of sera obtained by each centre, was plotted against the month of onset of lymphadenopathy (fig 2 ). The maximal response occurred at about two months, and specific IgM could be detected for about six months after onset of symptoms.

Fig 3 shows the results for the series of sequential specimens of serum taken during the course of a laboratory acquired infection. The initial IgM response was higher than that seen with the pooled data for the naturally acquired infections; it was maximal earlier at one to two months and became negative sooner at about four months. Figs 2 and 3 show that the results obtained by the three laboratories were very similar.

\section{Discussion}

The use of the monoclonal antibody CIE3 has been shown to be effective in an antibody class capture system for the detection of specific IgM directed against T gondii. ${ }^{9}$ The CIE3 conjugate has several advantages over polyclonal antibody for the detection of bound antigen. It can be used at high dilutions with the potential of reducing both non-specific and background reactions, increasing the specificity and sensitivity. With the polyclonal serum conjugate used in an earlier version of the test, it was necessary to add carefully selected homologous serum to the diluent to reduce background reactions. With the monoclonal conjugate, BSA (which is more readily available than suitable human sera) can be substituted. To avoid false positive reactions due to rheumatoid factor in- teracting with the Fc portion of the immunoglobulin, it had been necessary to prepare conjugates from the $\mathrm{F}(\mathrm{ab})_{2}$ fragment when using polyclonal antibodies. ${ }^{2}$ False positive reactions were not observed in the present study when testing sera containing rheumatoid factor with conjugates prepared from the intact CIE3 monoclonal antibody. Similar findings have been reported on the use of a monoclonal antibody for the detection of IgM specific for rubella. ${ }^{10}$ CIE3 conjugate slowly loses its titre when stored at $4^{\circ} \mathrm{C}$ but retains its full potency when stored in liquid nitrogen. The stability at $4^{\circ} \mathrm{C}$ is greatly improved when mixed with the Toxoplasma antigen. No loss of titre could be detected in a conjugate and antigen mixture after nine months' storage at this temperature. Prior mixing of the conjugate and antigen has the added advantage of removing an incubation stage of the assay.

CIE3 antibody has been shown to recognise a major cell membrane component of $T$ gondii against which IgM is produced in the course of human toxoplasmosis. It has also been shown to give a high level of protection in mice against infection with this organism (unpublished data). Although very high dye test titres are found with CIE3 antibody, the indirect haemagglutination test is completely negative. Many different antigen preparations were used during the development of this assay, but the egg-derived antigen described consistently gave the greatest distinction between positive and negative results. The high sensitivity of the assay enables patients' sera to

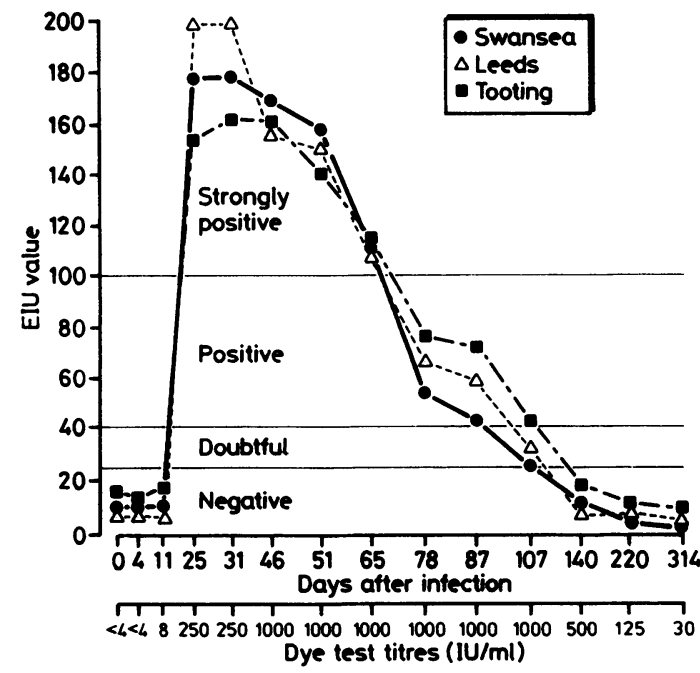

Fig 3 Estimation of $\mathrm{Ig} M$ titres in sequential serum specimens from case of laboratory acquired toxoplasmosis: corresponding dye test titre for each specimen is shown. 
be tested at a dilution of $1 / 1000$. This has the clinical advantage of requiring only a very small sample and may be of considerable importance when investigating congenital infection. It also greatly reduces the possibility of a false positive result due to the patients' serum cross reacting.

Expression, standardisation, and interpretation of results in any ELISA system is an area of contention. The Leeds PHL have used the EIU system to assess results for some time, and it has now been adopted by the three Toxoplasma Units. The results are recorded in EIUs and interpreted as either negative, doubtful, positive, or strongly positive depending on the EIU obtained. A general comment is then given on the overall serological pattern, with particular respect to any information on the request form, to aid the clinician in interpreting the report. Expressing results as EIUs permits direct comparison of assay runs, irrespective of absolute absorbance values, and has proved valuable for attempting comparisons of different assay formats. Problems of too much or too little substrate colour development are also largely eliminated, with full controls on each microtitre plate. When the results were assessed visually, most sera could be correctly classified without reference to absorbance values. The only contentious results were those in the doubtful category, and these are always repeated.

We consider that the work described here clearly shows that this rapid simplified assay, is sensitive, robust, and reproducible - comparable results being obtained at the three centres, even though different equipment was used at each. The assay will provide, therefore, a standard against which other assays can be measured.
We are indebted to Mr BS Chessum for helpful criticism and advice.

\section{References}

1 Naot Y, Remington JS. An enzyme-linked immunosorbent assay for detection of IgM antibodies to Toxoplasma gondii use for diagnosis of acute acquired toxoplasmosis. J Infect Dis 1980; 142:757-66.

2 Payne RA, Isaac M, Francis JM. Enzyme-linked immunosorbent assay (ELISA) using antibody class capture for the detection of antitoxoplasma IgM. J Clin Pathol 1982;35:892-6.

3 Duermeyer W, Wielaard F, van der Veen J. A new principle for the detection of specific IgM antibodies applied in an ELISA for hepatitis A. J Med Virol 1979;4:25-32.

4 Fleck DG, Kwantes W. The laboratory diagnosis of toxoplasmosis, Public Health Laboratory Service monograph 13. London: HMSO, 1980.

5 Wilson MB, Nakane PK. Recent developments in the peroxidase method of conjugating horseradish peroxidase to antibodies. In: Knapp W, ed. Immunofluorescence and related techniques. Amsterdam: Elsevier, 1978:215-24.

6 Fleck DG, Payne RA. Tests for toxoplasma antibody. Monthly Bulletin of the Ministry of Health Laboratory Service 1963;22:97.

7 Turunen H, Vuorio KA, Leinikki PO. Determination of IgG, IgM and IgA antibody responses in human toxoplasmosis by enzyme-linked immunosorbent assay (ELISA). Scand J Infect Dis 1983;15:307-11.

8 Tedder RS. Laboratory investigation of rubella. PHLS monograph 16. London: HMSO, 1982.

9 Balfour AH, Harford JP. Use of monoclonal antibody in an ELISA system for the detection of IgM class antibody specific for Toxoplasma gondii. J Clin Pathol (in press).

10 Morgan-Capner $P$. The detection of rubella-specific antibody. PHLS Microbiology Digest 1983;1:6-10.

Requests for reprints to: Dr DHM Joynson, Public Health Laboratory, Singleton Hospital, Sgeti, Abertawe, Swansea, SA2 8QA. 